\title{
Will Ageing Lead to a Higher Real Exchange Rate for the Netherlands?
}

\author{
Casper van Ewijk • Maikel Volkerink
}

Received: 18 November 2011 / Accepted: 2 December 2011 / Published online: 8 January 2012 (C) The Author(s) 2012. This article is published with open access at Springerlink.com

\begin{abstract}
Long term projections for the Netherlands indicate that demand for nontradables-e.g. health care services-will increase relative to supply due to population ageing. If this leads to higher future real exchanges rates this will erode the return of the savings currently made to prepare for ageing. This paper explores the magnitude of potential price effects using a modified version of the two country, four commodity framework developed by Obstfeld and Rogoff (Brookings Papers Econ Activity 1:67-146, 2005) to explore the exchange rate effects of the balance of payments reversal in the US. When these price effects are substantial this may have serious consequences for policies to enhance national saving in the Netherlands.
\end{abstract}

Keywords Ageing $\cdot$ Trade balance $\cdot$ Nontradables $\cdot$ Real exchange rate

JEL Classification $\quad \mathrm{E} 60 \cdot \mathrm{F} 41 \cdot \mathrm{J} 11$

Electronic supplementary material The online version of this article

(doi:10.1007/s10645-011-9182-5) contains supplementary material, which is available to authorized users.

C. van Ewijk $(\varangle)$

CPB Netherlands Bureau for Economic Policy Research, Netspar and University of Amsterdam, Amsterdam, The Netherlands

e-mail: c.vanewijk@uva.nl

M. Volkerink

SEO Economic Research, Amsterdam, The Netherlands

e-mail: m.volkerink@seo.nl 


\section{Introduction $^{1}$}

The Netherlands has run a surplus in the balance of payments since the beginning of the 1980s. Accumulated savings are welcome in view of the upcoming burden of population ageing in next decades. There are concerns, however, that the return on these savings may be eroded by higher prices when ageing comes true. There are two reasons why ageing - for a small open economy_may lead to higher (real) prices for domestic goods. First, population ageing will shift average preferences from tradables to nontradables as older people demand more domestic services than goods, in particular services related to health care and long term care. The increasing demand for nontradables may drive up prices if supply is restrained. Second, and more typical for the case of the Netherlands, future consumption will increase relative to domestic output when accumulated foreign savings are repatriated to keep up consumption for the ageing population. Long term projections for the Netherlands indicate that the trade balance will turn from a surplus of 7\% of GDP in 2010 into a deficit of 3\% when ageing reaches its peak in 2040 . This reversal in the trade balance may affect domestic prices as demand for domestic goods increases relative to output.

In this paper we explore the scope and magnitude of (real) price effects on the intertemporal price of consumption in a simple stylized model for the Netherlands. In the projections underlying Dutch fiscal policies (Van der Horst et al. 2010, Bettendorf et al. 2011) any such price effects are neglected. Adopting a small open economy perspective, these projections assume prices to be given by world market prices. Although there are good reasons to assume that the economy is sufficiently flexible to eliminate any price effects in the long run, it is useful to explore the potential impact for more conservative views on the flexibility of the economy. If price effects do occur the projections tend to overstate the effectiveness of policies aiming at increasing national saving for ageing, as the rate of return on these savings may be eroded by higher future consumer prices. These price effects matter for fiscal policy, not only because they impact the government budget directly through the costs of government expenditures, but also because they alter the costs and benefits of austerity policies to restore sustainability. Accordingly, budgetary policies become less effective for the purpose of consumption smoothing over generations.

In many respects the future unwinding of the Dutch trade balance surplus mirrors the problem of reversal in US current account that has been analysed by Obstfeld and Rogoff (2005). It is in opposite direction, though; while rebalancing of the US balance of payments requires the elimination of the current account deficit, rebalancing in the case of the Netherlands implies the transition from a surplus to a deficit. Accordingly, whereas the US faces a real depreciation, the Netherlands will-in the future-experience in increase in the real exchange rate. Obstfeld and Rogoff (O\&R) conclude that the dollar needs to depreciate by $20-25 \%$ to eliminate the current account deficit of about $6 \%$ of GDP in 2005. For the Netherlands the challenge is almost twice as large as the trade balance will change by $10 \%$ in total. If the price effect would be in proportion, this would imply a yearly real price increase of around $1 \%$ for the Netherlands

\footnotetext{
1 Comments by Nick Draper and computational assistance by Arie ten Cate are gratefully acknowledged
} 
relative to the rest of the world during the entire period 2010-2040. This enormous price effect would however overstate the problem, as over a longer time horizon also supply can be expected to adjust, so that price effects are softened.

In this paper we will adopt the O\&R framework to analyse the Dutch case, but with some important modifications. O\&R assume a symmetric two region world (home- foreign) with four heterogeneous types of goods: home and foreign produced tradables, and nontradables in both countries, with fixed labour endowments for each sector. This framework will be modified for the case of a small open economy, so that the price of foreign tradables can be taken as given. Furthermore, since our focus is on the long term we drop the assumption of fixed sectoral endowments, and allow for factor mobility between the two domestic sectors. Finally, we will allow preferences to change over time, thus taking account of the increasing share of nontradables in aggregate consumer spending due to the ageing population, In other respects, we will follow O\&R. Although the model is static in nature, we can use it for comparative statics by accounting for the evolution of the relevant variables using long term projections for the Dutch economy constructed by Van der Horst et al. (2010). This allows us to derive both the terms of trade effects, and price effects of domestic nontradables at different points in time in the future; we focus on 2040 when ageing reaches its peak, and the intermediate year 2025 .

Naturally, the impact of demand on relative prices over such a long time horizon is uncertain. It is often argued that over such a long time horizon factor mobility will eradicate all price differentials. Yet, terms of trade effects seem to be quite persistent, even over longer time horizons ( $c f$. Cardi and Restout 2011)). And there is ample evidence on imperfect mobility on labour market. Lee and Wolpin (2006) find that switching across sectors does involve substantial costs to the individual ranged between 50 and $75 \%$ of annual earnings. Also flexibility upon entry in the labour market is less than perfect due to individual heterogeneity. Moreover, students seems to take little notice of wage differentials when choosing their type of study (Oosterbeek and Webbink 1995). A the same time we see that wage ratios vary little in response to sectoral shifts. For example, while in the US the services sector employment in the period 1968-2000 grew 2.2\% per year faster than in the goods industries, wages grew by only $0.2 \%$ faster. Possibly, organization of production in tasks and its spatial distribution may be more flexible than traditional sectoral models predict (Baldwin and Robert-Nicoud 2010). In summary, there is a lot uncertainty on these issues, and the alternative positions on long-term price effects seem to be a matter of belief rather than of solid knowledge. Although we are inclined to think that price effects are minor of a long time horizon, we believe it is useful to contribute to this debate by exploring the potential magnitude of such effects, and to gain insight into the sensitivity of the results to underlying assumptions.

Our analysis is related to the literature on the growth of the services sector relative to the goods industries (e.g., Iscan 2009), but only partially. In the present paper, we take underlying trends as given, and focus on the partial effects of ageing on relative prices across sectors. This is reasonable as our concern relates to policies aimed at enhancing national savings to prepare for ageing, for which the marginal effects matter.

The paper is organized as follows. Section 2 introduces the long term scenario's for the Netherlands, and derives aggregate consumer preferences for tradables and 


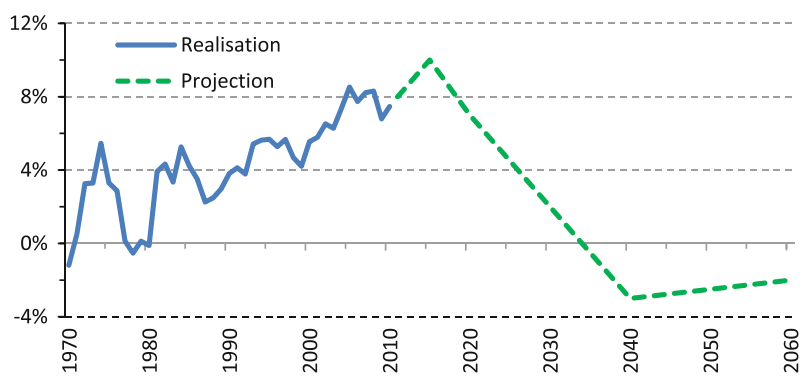

Fig. 1 Trade Balance (\% GDP), historical and projected. Source: CBS (2011) for historical data; Van der Horst et al. (2010) for projections

nontradables on the basis of household data. Section 3 presents the model, and Sect. 4 presents the calibration and the numerical results for the medium term (the year 2025) and the long term (the year 2040).

\section{Some Stylized Facts}

From 1970 to 2010 the Netherlands has consistently built up a trade surplus from $0 \%$ in 1970 percent to $7 \%$ in 2010 (Fig. 1). As a result the Netherlands has accumulated a net foreign asset position of about 30\% of GDP by 2010 (DNB 2011). The trade surplus is projected to remain high up to 2020; thereafter it steadily declines and turns into a deficit by 2040 when the demographic transition towards a greyer society is completed. This time path is consistent with a sustainable path of government finances which starts with a surplus in anticipation of the growing burden of pensions and other age related expenditures in the future. The deterioration in the trade balance is the net result of two effects of ageing: first, on the supply side output growth is restrained by the decline in working population, and second, on the demand side accumulated savings keep up purchasing power to smooth consumption when people become older on average. The reversal of the trade balance after 2030 is thus the natural complement of the ageing process.

When aggregate demand increases relative to output, domestic prices may rise as a result leading to an increase in the real exchange rate as well. How much domestic prices rise depends on how easy it is to substitute imported commodities for domestic goods and services. In case of perfect substitutability domestic prices will be fixed by prices on world markets, but with low substitution possibilities prices may rise sharply. It is useful here to make a distinction between tradables and nontradables; tradables are sold both home and abroad whereas nontradables are supplied to the home market only. Restrictions on tradability follow from characteristics of the good (like a haircut or nursing), or institutional constraints like tariffs. It is generally assumed that higher domestic demand will in particular affect prices of nontradables- being fully determined on the home market -, though it may lead to higher prices of 'home' produced tradables as well. 


\subsection{Age Dependent Consumption Patterns}

There is a second reason why demand for domestic nontradables will increase. Since older people spend more on domestic services than young people, ageing will also affect the aggregate preferences with regard to nontradables and tradables. This may be an additional factor driving up domestic prices. In the extreme, it is feared that growing demand for non-tradable services like long term care and healthcare will make old age of current generations unaffordable. This is clearly overstated, but it is true rising costs of age related expenditures may put additional pressure on the ageing problem.

Empirical research on expenditure patterns of age-groups is still scarce. BörschSupan (2001) takes a brief look at the relation between age and consumer spending. By comparing budget shares for different consumption categories per age-group over time, he finds that consumption profiles differ across age indeed. Hobijn and Lagakos (2003) come to similar conclusions. ${ }^{2}$ For instance, they find that budget shares for medical care by the elderly are twice as large as those of people of working age. Purchases on transportation, on the other hand, fall by a third. A problem in this type of research is that it cannot strictly separate time, cohort and age effects. Nevertheless Börsch-Supan suspects that age is the main determinant of the changes in spending behaviour; repeated cross-sectional analysis showed that the age-consumption profiles did not change much across age-groups during the 1980s and 1990s. Lührmann (2005, 2008) has looked more carefully at this issue by controlling for age and time effects. She finds that both age and time effects matter, but age-effects are most substantial.

\subsection{Age-Profiles of Tradables-Nontradables Consumption in the Netherlands}

In this paper we follow Börsch-Supan (2001) and derive age-consumption profiles using cross-sectional micro-data on household spending. Figure 2 presents budget shares per age group for the Netherlands for total expenditures, that is private and public expenditures combined. ${ }^{3}$ As expected, the elderly spend a considerable larger part of their budget on healthcare and related goods and services. This increase in healthcare expenditures is compensated by smaller budget shares for transportation, leisure and education and clothing.

Detailed private consumption data, provided by Statistics Netherlands (CBS 2010), makes it possible to distinguish between (manufactured) goods and services. Each of the 450 categories is classified as either tradable or nontradables; with a few exceptions, goods are classified as tradables and services are classified as nontradables. ${ }^{4}$ Public expenditures (on account of the consumer) is introduced as a separate category. Though we suspect most government services to be non-tradable, the extend cannot be determined from the data. Data on government expenditures per age follows from

\footnotetext{
2 However their research question is different. Hobijn and Lagakos criticise the consumer price index (CPI) that is used to index retirees' benefits.

3 Details on this decomposition are given in the appendix which is available on request.

4 See the appendix (available on request) for details.
} 


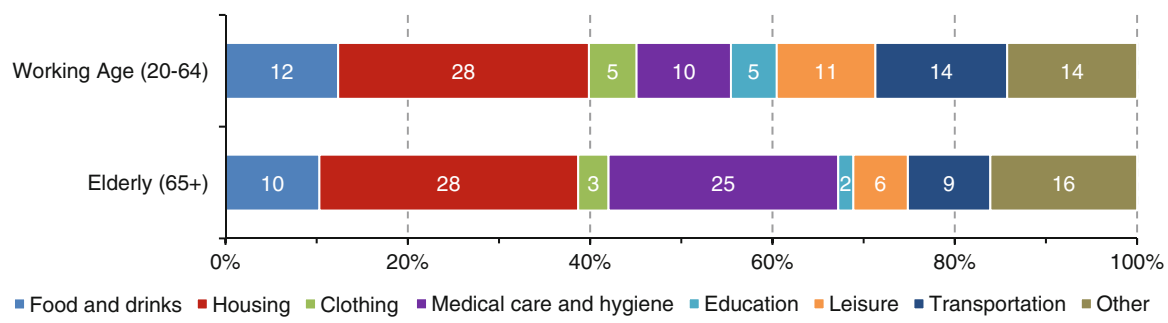

Fig. 2 Budget shares total household spending (public and private) per age group. Source Own calculations based on CBS (2010), Eurostat (2011) and Van der Horst et al. (2010)

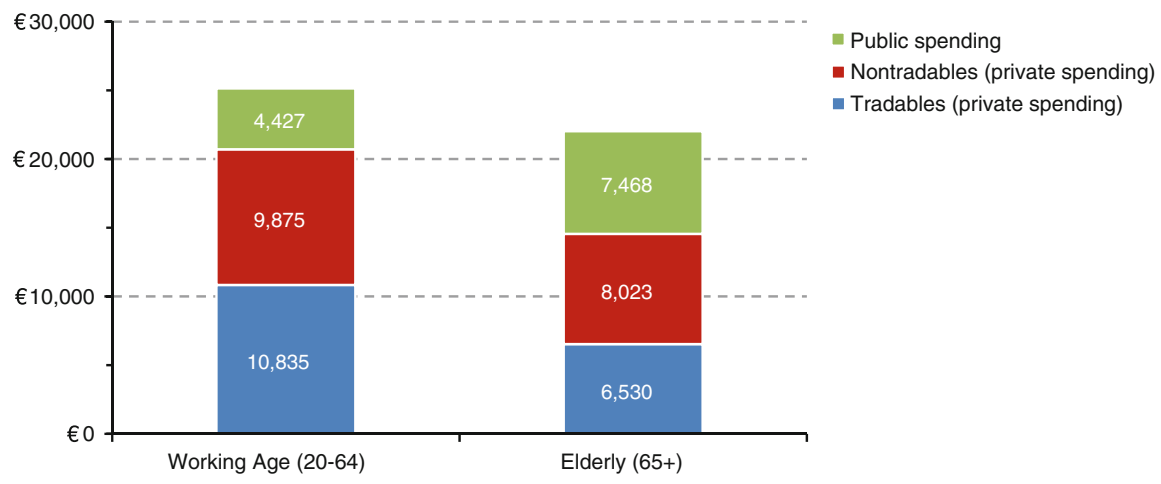

Fig. 3 Average expenditures per person, three categories, per age group. Source: own calculations based on CBS (2010), Eurostat (2010) and Van der Horst et al. (2010)

Van der Horst et al. (2010). Expenditures on education are high for the young, health expenditures are substantial for the elderly. Expenditures on infrastructure, government services (like public administration and parliament) are distributed equally over the population.

Results of this reclassification for the consumption profile per age category are presented in Fig. 3. The figure shows that elderly spend more on nontradables relative to tradables. In particular the large share of public spending for the elderly stands out.

Given these budget shares per age category and the Dutch demographic projections it is possible to calculate aggregate spending on each of these categories per year (see Table 1). The share of private consumption of tradables decreases from $40.5 \%$ in 2010 to $39.5 \%$ in 2025 , and $38.7 \%$ in 2040 . This mainly reflects the increase in public expenditures; this increases from $20.8 \%$ in 2010 to $23.0 \%$ in 2040 , an increase of $2.2 \%$ points while private consumption of tradables decreases by $1.8 \%$ points.

\subsection{Alternative Scenario: High Growth of Care Expenditures}

Table 1 expresses the demographic effects on spending shares only. That is, it takes account of the age effects, and neglects possible time effects on consumer preferences. Furthermore, differential effects of technological change are not accounted for either. Some people expect that expenditures on health care and long term care will grow 
Table 1 Projected budget shares for tradables and nontradables, 2010-2040

\begin{tabular}{llll}
\hline & $2010(\%)$ & $2025(\%)$ & $2040(\%)$ \\
\hline Share tradables (private consumption) & 40.5 & 39.5 & 38.7 \\
Share nontradables (private consumption) & 38.7 & 38.5 & 38.3 \\
Share public spending & 20.8 & 22.0 & 23.0 \\
\hline
\end{tabular}

Source Own calculations based on CBS (2010); Eurostat (2010) and Van der Horst et al. (2010)

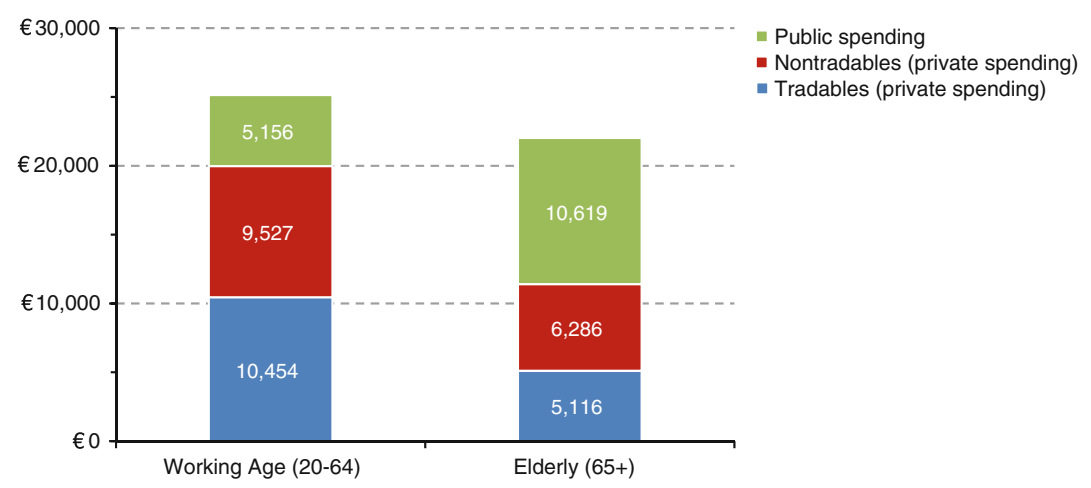

Fig. 4 Average expenditures per person, per age group in 2040: high growth of care scenario. Source: own calculations based on CBS (2010); Eurostat (2010) and Van der Horst et al. (2010)

Table 2 Projected budget shares tradables and nontradables: high growth of care scenario

\begin{tabular}{llll}
\hline & $2010(\%)$ & $2025(\%)$ & $2040(\%)$ \\
\hline Share tradables (private consumption) & 40.5 & 38.1 & 35.6 \\
Share nontradables (private consumption) & 38.7 & 37.1 & 34.8 \\
Share public spending & 20.8 & 24.8 & 29.6 \\
\hline
\end{tabular}

Source Own calculations based on CBS (2009, 2010); Eurostat (2010) and Van der Horst et al. (2010)

faster due to rapid improvement in medical technology, and possibly due to Baumol and Wagner effects ${ }^{5}$ as well. Therefore we will consider an alternative scenario with high growth of public expenditures next to our baseline scenario. Van der Horst et al. (2010) distinguish an alternative scenario with $1 \%$ extra growth per year in public expenditures on healthcare and long term care for the period 2010-2040. This will lead to a dramatic increase in total public expenditures by 2040 as can been seen from Fig. 4.

Though these assumption are rather extreme, they provide an informative benchmark. Again we can calculate the evolution of aggregate spending shares for the high care expenditures scenario, see Table 2. In this case the share of tradables in total spending decreases by no less than $4.9 \%$ points.

5 The Baumol effect refers to lower productivity change, and the Wagner effect to an income elasticity larger than one. Both factors may lead to a larger share of health care and long term care in total spending. 


\section{The Model}

How demographic transition affects prices of nontradables and tradables can be explored using a modified version of the two-country model of Obstfeld and Rogoff (2005). Like Obstfeld and Rogoff (O\&R) we use the model to analyse the impact of a change in demand on prices and the real exchange rate. The context is different though. While O\&R use the model to assess the impact of an unwinding of the US current account deficit in the short run, we will focus on the reversal in the trade balance as ageing proceeds in the long run. In addition, ageing may also lead to a shift in consumption of tradables to nontradables as demand for old age care increases. The long term character of our problem requires the O\&R model to be modified in one important respect: whereas $O \& R$ assume production in each sector to be completely fixed, we will allow for flexibility in production in the medium and long term. In particular we drop the assumption of a fixed allocation of labour, and introduce long term mobility of labour across sectors. The total endowment of labour remains fixed. Furthermore, we focus on a small country relative to the rest of the world; this country is a price taker on foreign capital markets and markets for foreign tradables. Capital is perfectly mobile internationally. In other respects the model is similar, featuring two-countries (home versus the rest of the world), two-sectors (tradables and nontradables) and home bias as consumers prefer domestically produced tradables over tradables produced abroad. The model can be summarized as follows.

\subsection{Prices}

The demand side of the model specifies nested preferences of consumers with regard to the nontradables $C_{N}$ and tradables $C_{T}$, with tradables being a composite of domestically produced tradables $C_{H}$ and foreign tradables $C_{F} \cdot{ }^{6}$ Using standard CES preferences one obtains the following prices for total domestic consumption $(P)$ and the price of tradables $P_{T}$.

$$
\begin{aligned}
P & =\left[\gamma P_{T}^{1-\theta}+(1-\gamma) P_{N}^{1-\theta}\right]^{\frac{1}{1-\theta}} \\
P_{T} & =\left[\alpha P_{H}^{1-\eta}+(1-\alpha) P_{F}^{1-\eta}\right]^{\frac{1}{1-\eta}}
\end{aligned}
$$

6 Consumer preferences with regard to nontradables and tradables are given by the CES function (for the home country) $C=\left[\gamma^{\frac{1}{\theta}} C_{T}^{\frac{\theta-1}{\theta}}+(1-\gamma)^{\frac{1}{\theta}} C_{N}^{\frac{\theta-1}{\theta}}\right]^{\frac{\theta}{\theta-1}}$ where $\gamma$ represents the share spent on tradables, and $\theta$ the elasticity of substitution. In this function tradables $C_{T}$ is a composite commodity depending on Home and Foreign produced goods, $C_{H}$ and $C_{F}$, given by $C_{T}=\left[\alpha^{\frac{1}{\eta}} C_{H}^{\frac{\eta-1}{\eta}}+(1-\alpha)^{\frac{1}{\eta}} C_{F}^{\frac{\eta-1}{\eta}}\right]^{\frac{\eta}{\eta-1}}$ and for the foreign country $C_{T}^{*}=\left[\alpha^{* \frac{1}{\eta}} C_{F}^{* \frac{\eta^{*}-1}{\eta^{*}}}+\left(1-\alpha^{*}\right)^{\frac{1}{\eta^{*}}} C_{H}^{* \frac{\eta^{*}-1}{\eta^{*}}}\right]^{\frac{\eta^{*}}{\eta^{*}-1}}$ with elasticity $\eta$ and preference for domestic tradables $\alpha$. As the two countries are of unequal size foreign country (indicated by asterisks) may have different $\alpha$ and $\gamma$ coefficients: $\alpha<\alpha^{*}, \gamma>\gamma^{*}$. 
The price of consumption $P$ depends on the prices for tradables $P_{T}$ and nontradables $P_{N}$, and similarly the price of tradables $P_{T}$ depends on prices of Home goods and Foreign goods, $P_{H}$ and $P_{F}$. The preference parameters $\gamma$ and $\alpha$ represent the shares spent on tradables and Home goods. Also, $\theta$ and $\eta$ give the elasticities of substitution between consumption of tradables $C_{T}$ and nontradables $C_{N}$, and Home and Foreign produced goods, $C_{H}$ and $C_{F}$, respectively. With respect to tradables it is assumed that the law of one price holds, that $P_{F}=P_{F}^{*}$ and $P_{H}=P_{H}^{*}$ where the asterisk denotes foreign variables. All prices are expressed in the same currency so that we can neglect nominal exchange rates. Note that the law of one price does not hold for baskets of tradables - as shares may differ -, and a fortiori for prices of nontradables and the general price level $P$, so $P_{T} \neq P_{T}^{*}$, and $P \neq P^{*}$. The small open economy assumption implies that changes in prices in the home country have a negligible impact on foreign prices as well as foreign consumption. The price of foreign tradables $\left(P_{F}\right)$ is therefore taken as numeraire. Next define the following relative prices:

$$
\begin{array}{ll}
\tau=P_{F} / P_{H} & \text { (terms of trade) } \\
x=P_{N} / P_{T} & \text { (relative price of nontradables) }
\end{array}
$$

More than in these static prices, we are in this paper interested in the intertemporal terms of trade, that is the real interest rate $r$ on national savings. This depends on the given world interest rate $r^{*}$ (expressed in units of foreign tradables) and the real rate of appreciation:

$$
1+r=\left(1+r^{*}\right) / P \quad(\text { real interest rate })
$$

where the initial exchange rate-measured today-is normalized at unity. Higher future prices $P$ thus imply a lower interest rate and thus worsen the intertemporal terms of trade. Obviously as ageing happens in the rest of the world as well, the world interest rate reflects the impact ageing as well. What matters for our analysis however is how domestic policies towards ageing affect the effective interest rate on national savings. In other words, do policies to promote national savings in the advent of ageing deteriorate the terms of trade, or in popular terms: will not future price rises due to scarcity of domestic goods erode the value of our savings for old age?

\subsection{Demand and Supply}

Prices can be solved from demand and supply for the two domestically produced goods $C_{N}$ and $C_{H}$. Optimising consumer behaviour-given the budget constraint $P C=P_{T} C_{T}+P_{N} C_{N}$ - leads to the following demand equations:

$$
\begin{aligned}
& \frac{C_{N}}{C_{T}}=\frac{1-\gamma}{\gamma}\left(\frac{P_{N}}{P_{T}}\right)^{-\theta} \\
& \frac{C_{F}}{C_{H}}=\frac{1-\alpha}{\alpha}\left(\frac{P_{F}}{P_{H}}\right)^{-\eta}
\end{aligned}
$$


Next consider the supply side. As we focus on the long run we have to modify the O\&R model in one important respect. Rather than assuming a fixed endowment economy we allow for flexibility in production factors across sectors. More specific, we assume labour to be mobile. This flexibility is not perfect, as workers have preferences for working in either sector. This could be interpreted that workers are heterogeneous and that each sector requires specific skills which cannot be acquired costlessly. Even though ageing is a process that will take several decades to reach its peak, the working population can only slowly adjust to new requirements with regard to skills. We capture this by the following relation for the allocation of labour to the tradable sector $L_{H}$ and nontradables sector $L_{T}$ :

$$
\frac{L_{N}}{L_{H}}=\lambda\left(\frac{w_{N}}{w_{H}}\right)^{\psi}
$$

where $\psi$ represents the substitution elasticity of labour across sectors, and $\lambda$ the preference for working in the nontradables sector. ${ }^{7}$ Total labour supply is fixed by population size $L$, giving the resource constraint

$$
L=\frac{Y_{N}}{A_{N}}+\frac{Y_{H}}{A_{H}}
$$

where $Y_{i}$ and $A_{i}$ stand for production and average labour productivity in sector $i$ with $i \in\{N, H\}$, thus $Y_{i}=A_{i} L_{i}$. If capital can freely move between the two sectors, and production features constant returns to scale, wages in either sector are given by prices and average productivities, therefore

$$
\frac{w_{N}}{w_{H}}=\frac{A_{N} P_{N}}{A_{H} P_{H}}
$$

Adopting a simple Cobb Douglas production function $Y_{i}=K_{i}^{\frac{\beta}{1+\beta}}\left(M_{i} L_{i}\right)^{\frac{1}{1+\beta}}$ this labour productivity is given by

$$
A_{i}=\left(\frac{\beta}{1+\beta} \frac{1}{r} \frac{P_{i}}{P_{F}}\right)^{\beta} M_{i}
$$

where $r P_{F}$ stands for the rental price of capital goods, which are owned abroad. Collecting these results we can solve for production in the two sectors:

$$
\frac{Y_{N}}{Y_{H}}=\lambda\left(\frac{M_{N}}{M_{H}}\right)^{1+\psi}\left(\frac{P_{N}}{P_{H}}\right)^{\psi+\beta(1+\psi)}
$$

7 This follows from preferences with regard to work in either sector:

$U=\left[\frac{\lambda}{1+\lambda}^{\frac{1}{\psi}} L_{N}^{\frac{\psi-1}{\psi}}+\frac{1}{1+\lambda} \frac{1}{\psi} L_{H}^{\frac{\psi-1}{\psi}}\right]^{\frac{\psi}{\psi-1}}$ 
The production allocation varies with prices depending on labour elasticity $\psi$ and the capital elasticity $(\beta)$. Without loss of generality we can assume $M_{N} / M_{H}=1$ so that $\lambda$ captures both preferences and productivity.

\subsection{Aggregate Equilibrium}

Aggregate consumption depends on the intertemporal equilibrium of saving and wealth. As we focus on the prices effects of the reversal in the balance of trade, we take total wealth — and thus the amount people can spend on consumption-as given in terms of foreign prices. The volume of consumption, as well as its composition, are endogenously determined in aggregate equilibrium. In addition to this effect of ageing through the balance of trade effect, we also take account of the impact of ageing on aggregate consumer preferences, represented here by a shift in the share of tradables $\gamma$. The trade balance is given by

$$
B=P_{H} Y_{H}-P_{T} C_{T}
$$

Using the demand equations (3) and (4) and the condition that in equilibrium production of home tradables must equal the sum of domestic and foreign demand, $Y_{H}=$ $C_{H}+C_{H}^{*}$ this can be written as

$$
B=\frac{\left(1-\alpha^{*}\right)}{\alpha^{*} \tau^{1-\eta^{*}}+\left(1-\alpha^{*}\right)} P_{T}^{*} C_{T}^{*}-\frac{(1-\alpha) \tau^{1-\eta}}{\alpha+(1-\alpha) \tau^{1-\eta}} P_{T} C_{T}
$$

where the first term on the right hand side represents foreign demand for Home tradables (in value terms) and the second term net domestic demand for tradables. Normalizing this result to the given foreign consumption of tradables $P_{T}^{*} C_{T}^{*}$ gives:

$$
b=\frac{\left(1-\alpha^{*}\right)}{\alpha^{*} \tau^{1-\eta^{*}}+\left(1-\alpha^{*}\right)}-\frac{(1-\alpha) \tau^{1-\eta}}{\alpha+(1-\alpha) \tau^{1-\eta}} h
$$

where $h\left(=P_{T} C_{T} / P_{T}^{*} C_{T}^{*}\right)$ represents the size of domestic consumption of tradables relative to world consumption of tradables. This variable depends on aggregate demand in the economy, which is determined by the trade balance $b$. This result should be interpreted as follows: the richer the country is, the larger deficit in the trade balance it can afford, and the more it can spend on consumption.

Finally, the model is closed by the equilibrium for demand and supply of domestically produced nontradables and tradables. Demand for domestic tradables $Y_{H}$ from home and foreign consumers (using $Y_{H}=C_{H}+C_{H}^{*}$ and the demand equations (3) and (4) again) can be written as:

$$
P_{H} Y_{H}=\frac{\left(1-\alpha^{*}\right)}{\alpha^{*} \tau^{1-\eta^{*}}+\left(1-\alpha^{*}\right)} P_{T}^{*} C_{T}^{*}+\frac{\alpha}{\alpha+(1-\alpha) \tau^{1-\eta}} P_{T} C_{T}
$$


Table 3 Evolution of exogenous variables over time

\begin{tabular}{|c|c|c|c|c|}
\hline \multicolumn{2}{|l|}{ Exogenous variables } & \multirow{2}{*}{$\frac{2010}{7 \%}$} & \multirow{2}{*}{$\frac{2025}{4 \%}$} & \multirow{2}{*}{$\frac{2040}{-3 \%}$} \\
\hline Trade balance at constant prices ( $\%$ GDP) & $b^{\prime}$ & & & \\
\hline Share of tradables in domestic consumption (baseline) & $\gamma$ & 0.405 & 0.395 & 0.387 \\
\hline Share of tradables in domestic consumption (high care scenario) & $\gamma$ & 0.405 & 0.381 & 0.356 \\
\hline
\end{tabular}

Supply of Home tradables follows from the resource constraint for labour (6) and the production allocation (8). Upon substitution for $Y_{H}$ one obtains the condition:

$$
\frac{q}{1+\lambda p_{n}^{\psi(1+\beta)}}=\left[\frac{1-\alpha^{*}}{\alpha^{*} \tau^{1-\eta^{*}}+\left(1-\alpha^{*}\right)}+\frac{\alpha}{\alpha+(1-\alpha) \tau^{1-\eta}} h\right] \tau^{1+\beta}
$$

where $p_{n}=P_{N} / P_{H}$, and $q$ collects the exogenous terms, $q=\frac{M_{H} L}{P_{T}^{*} C_{T}^{*} / P_{F}}$ indicating the size of the domestic economy relative to the rest of the world. Similarly, equilibrium between supply and demand for nontradables, $C_{N}=Y_{N}$, can be found to require:

$$
\frac{q \lambda p_{n}^{\psi(1+\beta)}}{1+\lambda p_{n}^{\psi(1+\beta)}}=\frac{1-\gamma}{\gamma} x^{1-\theta}\left(\frac{\tau}{p_{n}}\right)^{1+\beta} h
$$

where again the left hand features supply and the right hand demand which depends on prices $\tau, x$ and aggregate demand represented by $h$. Finally, noting that the price of nontradables to home tradables $p_{n}$ relates to the terms of trade $\tau$ and the price of nontradables to tradables $x$ as from (2):

$$
p_{n}=x\left[\alpha+(1-\alpha) \tau^{1-\eta}\right]^{\frac{1}{1-\eta}}
$$

It can be concluded that Eqs. (9)-(12) solve the model in terms of the endogenous price variables $x, \tau, p_{n}$ and the size of tradables consumption $h$ for any given value of the trade balance $b$.

\section{Simulations}

In contrast to Obstfeld and Rogoff (2005) who apply their model to the case of the US in the short run, we focus on the case of a small open economy in the medium to long run. In particular we take the case of the Netherlands as a starting point. For many years the Netherlands has run a large surplus in its current account yielding an accumulation of foreign assets. These assets will be used for consumption as ageing progresses. At the same time the share of nontradables consumption increases as a results of ageing. Table 3 gives the evolution of two exogenous variables that determine the change in demand for tradables and nontradables over time. These data follow from Fig. 1 and Tables 1 and 2 in Sect. 1. 
For expositional reasons Table 3 expresses the trade balance as a percentage to GDP (indicated by $b^{\prime}$ ) rather than world consumption as in the model (denoted by $b$ ). ${ }^{8}$ From a surplus of $7 \%$ of GDP the trade balance is projected to fall to $4 \%$ in 2025 , and a deficit of $3 \%$ in 2040 when ageing reaches its peak. This reflects the increasing consumption out of wealth when population on average becomes older. The increasing weight of the elderly also changes the composition of consumption. For the share of tradables in consumption $(\gamma)$ we follow Table 1 for the baseline scenario and Table 2 for the alternative scenario with high growth of healthcare expenditures. As elderly spend more on nontradables (services) the share of tradables decreases from $40.5 \%$ in 2010 to $38.7 \%$ in 2040 in the baseline scenario. Admittedly, the share of tradables may be underestimated as a part of public spending might be tradable. On the other hand Obstfeld and Rogoff (2005) emphasize that figures based on micro data like the Dutch household survey tend to overestimate the weight of traded goods as they neglect the fact a substantial component in the value of tradables actually concerns nontradable services. For that reason Obstfeld and Rogoff adopt a low value of $\gamma=0.25$ (or 25\%). Our estimate of $40.5 \%$ is higher, which makes sense for a small open economy as the Netherlands. In the alternative scenario with higher growth of long term care and healthcare expenditures the share of tradables even declines to $35.6 \%$ in 2040.

It should be noted that the figures for the trade balance are calculated under the assumption of constant domestic prices (Van der Horst et al. 2010). As domestic prices do vary in our analysis we have to take account of the impact of domestic prices on GDP as well. As a result the actual trade balance may worsen less than projected in Table 3 if GDP increases in value thanks to improving terms of trade. In solving the model we assume that the time path trade balance expressed in foreign prices is not affected. This makes sense as the trade balance follows from time path of the stock of net foreign assets given the intertemporal budget constraint, and assuming that the tilt of this time path is not affected itself. This seems the relevant benchmark for this exercise. ${ }^{9}$ To put it differently, if domestic prices rise, domestic consumers can buy fewer domestic goods in return for their accumulated savings. Accordingly, the real rate of return on savings decreases. Technically, this implies that the change in the trade balance is fixed in terms of foreign prices, but endogenous in domestic prices.

Furthermore, it should be taken into account that also the rest of the world faces ageing. This may increase demand for nontradables in the rest of the world as well. What matters, however, is to what extent the position of the Netherlands is distinct from the rest of the world, and it is clear that the Dutch economy features a substantial surplus in the trade balance, which can be expect to turn into a deficit in the long run. The change in demand between tradables and nontradables in the rest of the world is neutralized in our analysis by taking prices of foreign tradables as numeraire, also for the rate of return on international savings.

\footnotetext{
8 We assume that the size of the domestic economy relative to the world economy is constant over time in the underlying original projection. Then we can rescale the trade balance to GDP rather than world tradables consumption as in the model.

9 In this analysis we take private saving behaviour as given. Whether the higher intertemporal price of consumption induces higher or lower private savings depends on substitution and income effects.
} 
Table 4 Summary of other parameter variables

\begin{tabular}{|c|c|c|c|}
\hline \multicolumn{2}{|l|}{ Parameter } & \multirow{2}{*}{$\frac{\text { Baseline }}{0.5}$} & \multirow{2}{*}{$\begin{array}{l}\text { Alternatives } \\
0.25\end{array}$} \\
\hline Share of $\mathrm{H}$ goods in tradables consumption & $\alpha$ & & \\
\hline Share of F goods in tradables consumption (foreign) & $\alpha^{*}$ & 0.99 & \\
\hline Labour allocation nontradables-tradables & $\lambda$ & 1.239 & \\
\hline Size of the domestic economy (relative to world tradables) & $\mathrm{q}$ & 0.0387 & \\
\hline Elasticity of substitution $\mathrm{H}$ and $\mathrm{F}$ tradables & $\eta$ & 2 & $3 ; \infty$ \\
\hline Elasticity of substitution $\mathrm{H}$ and $\mathrm{F}$ tradables (foreign) & $\eta^{*}$ & 2 & $3 ; \infty$ \\
\hline Elasticity of substitution tradables and nontradables & $\theta$ & 1 & 2 \\
\hline Elasticity of substitution labour supply (medium term) & $\psi$ & 0 & \\
\hline Elasticity of substitution labour supply (long term) & $\psi$ & 1 & 10 \\
\hline Capital elasticity in production & $\beta /(1+\beta)$ & $1 / 3$ & \\
\hline
\end{tabular}

\subsection{Parameters of the Model}

For the parameters of the model we take Obstfeld and Rogoff (2005) as a starting point, but we have to adjust theirs to the case of the Netherlands. The resulting parameters are summarized in Table 4.

On the composition of consumption of tradables into Home and Foreign produced goods $(\alpha)$ there is little reliable information. The share of Dutch tradables production in ROW total tradables production is 0.015 . This may be considered as a lower boundary for the interval as home bias will make the share of Home good in consumption larger than this. On the high end it is clear that a small country as the Netherlands will feature a lower share of Home goods in consumption of tradables than the US. In the two country world Obstfeld and Rogoff (2005) assume $\alpha=0,7$. Taking this into consideration we will take $\alpha$ equal to 0.5 in the baseline, and equal to 0.25 in an alternative scenario with less home bias. A similar approach is followed for $\alpha^{*}$, the share of own goods (Foreign) in the ROW's consumption of tradables. Taking again the share of 0.015 of Dutch tradables in world tradables, and thus 0.985 as share for the rest of the world, and allowing for home bias a value of 0.99 for $\alpha^{*}$ seems reasonable. We assume that home bias does not change over time.

The parameters $q$ and $\lambda$ indicate the size of the economy. Taking all initial prices in the base year (2010) equal to one (index), $q$ stands for GDP of the country (relative to total ROW consumption of tradables to which all variables are scaled), and $\lambda$ for the size of the domestic nontradable sector $(N)$ relative to the tradable sector $(H)$. The size for these values are calibrated given the preferences and the size of the trade balance.

For the elasticities we rely on Obstfeld and Rogoff (2005). For the substitution elasticity of Home and Foreign tradables they use both a value of $\theta=1$ and $\theta=2$. According to empirical literature a value near $\theta=1$ is realistic. ${ }^{10} \mathrm{O} \& \mathrm{R}$ use the alter-

\footnotetext{
10 Ostry and Reinhart (1992) find estimates in the range of 0,66 and 1,3 for a sample of developing countries. For developed countries, values below 1 are more common (see Stockman and Tesar 1995 and Mendoza 1991).
} 
native value of 2 in their baseline not to overstate the price effects due to a change in the balance of trade. We will use these same values, also taking 2 as our baseline value. Regarding $\eta$ empirical research is thin. Pointing to prior work O\&R suggest values of $\eta=2$ and $\eta=3$ as being conservative but plausible. In addition, we also consider the case with infinite elasticity $(\eta=\infty)$, which reduces the model to the two-commodity case with nontradables and tradables only.

The elasticity of labour supply $(\psi)$ reflects the mobility of labour across domestic sectors. For the medium term (2025) we assume zero elasticity, and for the long term (2040) we choose $\psi=1$ in the baseline, and a higher elasticity of 2 in an alternative scenario. Although there is a wide literature on-the persistence of intersectoral wage differences-knowledge on the intersectoral elasticity of labour supply is scant. It is generally agreed that mobility across sectors is imperfect due to costs of mobility for those already in the labour market, and limited response of educational choice on wage differential for those who enter the labour market (Lee and Wolpin 2006). We follow Horvath (2000) estimate of an elasticity of 1 for the US. This is higher than the usual estimates for the elasticity of labour supply (Evers et al. 2008). It could be argued that European countries like the Netherlands feature lower elasticities. On the other hand, the long time horizon of our analysis makes a higher elasticity plausible. Balancing these arguments we think that the value of 1 is reasonable for the year 2040, but we will investigate the sensitivity of the results to this assumption using an alternative value of 10 . Finally, the elasticity of production with respect to capital $(\beta /(1+\beta))$ is equal to $1 / 3$, and therefore $\beta=1 / 2$.

\subsection{Two Scenario's: Baseline and High Costs of Care Scenario}

The demand shock induced by demographic change manifests itself through changes in the trade balance $(b)$ and the share of tradables in consumption $(\gamma)$. In general, the changes in demand will be greater in 2040 than in 2025, so one would expect more marked price effects as well. However, as supply is more elastic in the longer run, this will mitigate the price effects. Table 5 presents the results for the baseline scenario and for the alternative scenario with higher growth of care expenditures. Both scenario's feature a substantial increase in domestic prices. The aggregate consumer price $P$ goes up by $15 \%$ in de baseline and even $21 \%$ in the alternative scenario with high growth of care expenditures in 2040, that is a yearly price rise of 0.5 and $0.6 \%$, respectively. Since we have taken foreign prices as numeraire this price increase represents a real appreciation of the exchange rate for the Netherlands. Also the terms of trade improve as - due to the home bias_-demand for domestic tradables increases relative to foreign tradables although at a slightly lower pace, namely 9 and $11 \%$ in total in the baseline and the high care scenario.

The price rise of nontradables is reflected in the wages in the nontradables sector which increase by $17 \%$ relative to those in the tradables sector, that is $0.5 \%$ yearly. This is quite a substantial increase, although not unreasonable in comparison to the $0.23 \%$ rise reported by Lee and Wolpin (2006) for the services relative to goods industries in the US in the period 1968-2000. However, in that period in employment grew $2.23 \%$ faster in the services than in the goods industries. In our exercise employment grows 
Table 5 Results for the baseline and the high costs of care scenario, 2025 and 2040

\begin{tabular}{|c|c|c|c|c|c|c|}
\hline \multirow[t]{2}{*}{ Variable } & \multirow[t]{2}{*}{ Unit } & \multirow[t]{2}{*}{2010} & \multicolumn{2}{|c|}{ Baseline } & \multicolumn{2}{|c|}{ High care growth } \\
\hline & & & 2025 & 2040 & 2025 & 2040 \\
\hline Trade balance $\left(b^{\prime}\right)$ & $\%$ GDP & 7 & 3.6 & -2.4 & 3.5 & -2.2 \\
\hline Consumer price $(P)$ & Index & 1 & 1.07 & 1.15 & 1.10 & 1.21 \\
\hline Consumption $(C)$ & Index & 1 & 1.07 & 1.22 & 1.08 & 1.24 \\
\hline Price nontradables/tradables $(x)$ & Index & 1 & 1.10 & 1.17 & 1.14 & 1.23 \\
\hline Terms of trade $(\tau)$ & Index & 1 & 0.98 & 0.91 & 0.98 & 0.89 \\
\hline Output nontradables/tradables $\left(\sigma_{N}\right)$ & Index & 1 & 1.04 & 1.23 & 1.06 & 1.34 \\
\hline Wage nontradables/tradables & Index & 1 & 1.13 & 1.17 & 1.20 & 1.25 \\
\hline Employment nontradables/tradables & Index & 1 & 1.00 & 1.17 & 1.00 & 1.25 \\
\hline
\end{tabular}

by only by also $17 \%$ in total, and $0.5 \%$ yearly. One should be careful in comparing these figures, however. Here we only look at the partial effect of ageing on wages and employment, and we neglect all other trends that affect the share of the services industries in total production.

This real appreciation comes to the benefit of domestic producers. As a result total consumption increases by $22 \%$ in the baseline, and by even more in the high care scenario, namely $24 \%$. These beneficial effects arise from the increase in the prices of domestic products on world markets, and from the consequential shift in the domestic production allocation tradables to higher valued nontradables. The effects in GDP exceed the impact on consumption ${ }^{11}$, which is obvious as not all income can be translated into higher consumption since prices increase too. The positive impact on GDP also explains why the deficit in the trade balance turns out to be smaller ex post than in the projections with constant prices that was used as starting point of the scenario's, namely $-2.4 \%$ viz-a-viz the original figure of $-3 \%$.

The higher prices also affect the government budget. In particular, prices of nontradables matter as most government expenditures are on nontradables, e.g. health care or education. The price of nontradables can be found to increase by $22 \%$ in 2040 in the baseline and 30\% in the high care scenario. This clearly affects the government budget as it increases the costs of most expenditure programs. On a yearly basis this increases the costs by an additional $0.7-0.9 \%$ points. It is evident that this could have a dramatic effect on the sustainability of government expenditures, if taken partially. But that would neglect the fact that also the price increase goes hand in hand with additional growth of income as well. The net effect on public finances cannot easily be determined from the analysis at hand, but the size of the effects on prices, consumption and income (see footnote 11) suggest that it could go either way.

11 The GDP effects (not included in the table) are 27 and 35\%, respectively, in 2040. In 2025 these effects are relatively smaller (11 and 14\%) as lack of labour mobility inhibits production being reallocated to the higher valued nontradables sector. 
Table 6 Results for the case with higher elasticities in comparison to the baseline

\begin{tabular}{|c|c|c|c|c|c|c|}
\hline \multirow[t]{2}{*}{ Variable } & \multirow[t]{2}{*}{ Unit } & \multirow[t]{2}{*}{2010} & \multicolumn{2}{|c|}{ Baseline } & \multicolumn{2}{|c|}{ Higher elasticities } \\
\hline & & & 2025 & 2040 & 2025 & 2040 \\
\hline Trade balance $\left(b^{\prime}\right)$ & $\%$ GDP & 7 & 3.6 & -2.4 & 3.8 & -2.6 \\
\hline Consumer price $(P)$ & Index & 1 & 1.07 & 1.15 & 1.04 & 1.07 \\
\hline Consumption $(C)$ & Index & 1 & 1.07 & 1.22 & 1.06 & 1.17 \\
\hline Price nontradables/tradables $(x)$ & Index & 1 & 1.10 & 1.17 & 1.05 & 1.06 \\
\hline Terms of trade $(\tau)$ & Index & 1 & 0.98 & 0.91 & 0.99 & 0.93 \\
\hline Output nontradables/tradables $\left(\sigma_{N}\right)$ & Index & 1 & 1.04 & 1.23 & 1.02 & 1.27 \\
\hline Wage nontradables/tradables & Index & 1 & 1.13 & 1.17 & 1.07 & 1.02 \\
\hline Employment nontradables/tradables & Index & 1 & 1.00 & 1.17 & 1.00 & 1.26 \\
\hline
\end{tabular}

Next consider the medium term effects represented in the table for the year 2025. In this year the ageing process is still underway. Furthermore, production factors are less flexible over this shorter horizon than in the long term. Here we assume zero mobility of labour (not of capital) in the medium term. This can be seen from the last line in Table 5, stating that the allocation of labour over nontradables and tradables sectors is fixed in 2025, while in the long run (the year 2040) the ratio of employment in nontradables relative to tradables increases by $17 \%$. Accordingly, prices of nontradables react relatively stronger in the short run than in the long run. The terms of trade improve only by $2 \%$ in 2025 which is modest compared to the $9 \%$ in 2040, also if taken on a yearly basis. Also welfare-as measured by consumption - increases by much less than with flexible production as in the long run. The yearly increase in consumption is only $0.45 \%$ up to 2025 , while over the full period to 2040 it increases with 0.66 per year. For the high care scenario a similar story applies.

\subsection{Smaller Price Effects in a Flexible Economy}

The baseline scenario features quite conservative assumptions on the flexibility of the Dutch economy; for both the production side and the consumption side we have adopted elasticities at the lower bound of the interval. Table 6 presents the results for the more optimist view on the flexibility of the economy; we adopt a higher parameter for the mobility of labour across the two sectors $(\psi=10$ instead of $\psi=1)$, higher substitution elasticities for foreign versus home tradables $\left(\eta=\eta^{*}=0.03\right.$ instead of 0.02$)$ and for tradables versus nontradables as well $(\theta=2$ instead of $\theta=1)$.

In general, this alternative case gives broadly the same results. Thanks to the higher elasticities price effects are dampened while the relocation in production is larger. The increase in the real exchange rate more or less halves compared to the baseline, while the reallocation of labour almost doubles. Interestingly, the impact on relative wages is now even smaller in the long term than in the medium, even in absolute 
terms. Obviously this is due to the fact that we have raised the parameter for labour mobility in the long run, while keeping it zero for the medium term. Admittedly, zero mobility this is a strong assumption but it illustrates the fact that adjustment in the allocation of production factors is costly and time-consuming. ${ }^{12}$ In general, price effects dominate in the medium term while quantity adjustments are more important in the long run.

\subsection{Decomposition}

In order to gain insight into the underlying determinants of the price increases we perform two exercises, both reported in Table 7. First, we redo the baseline simulations, but now focusing on the impact of the trade balance solely. We thus neglect the increasing demand for nontradables related to the ageing process; in our model represented by the decline in the preference parameter $\gamma$. The results are reported in the first two columns. Comparison with the original baseline brings out that the reversal in the trade balance is by far more important than the age related change in composition of expenditure. For example, of the total increase in prices by $15 \%$, only $2 \%$ is due to changing preferences, while $13 \%$ is caused by the change in the trade-balance. Even the price of nontradables relative to home tradables is largely determined by the trade of balance effect, and not by the change in the composition of expenditures.

The last two columns in Table 7 provide insight into the importance of terms of trade effects. Here we assume that home and foreign produced tradables are perfect substitutes $\left(\eta, \eta^{*}=\infty\right)$, thus reducing the model to a two commodity case with nontradables versus tradables only. Naturally, the terms of trade $(\tau)$ are constant here, and the overall price rise $(P)$ is much smaller than in the baseline, namely $7 \%$ in contrast to $15 \%$ by 2040 . So terms of trade effects matter a lot for the overall price effect. For the sectoral allocation it has a negligible impact though, output of nontradables increases by $23 \%$ relative to home tradables, just as in the baseline. Also the wage effects are similar to the baseline.

\subsection{Sensitivity Analysis}

Since elasticities over a time horizon of a full generation are very uncertain, we will look in more detail into the sensitivity of the results for each of the parameters. Table 8 presents the partial effects for the main parameters reported for the year 2040. The alternative for the share of home goods in tradables $(\alpha)$ requires a new calibration ( $q=0.0284$ and $\lambda=1.239$, the variants in the elasticities did not. In general the effects are modest, and do not change the results in a qualitative way. Note that the effects are reported in percentage points relative to the baseline. As in all cases we increase elasticities - except in the first case where we lower home bias_-price effects

\footnotetext{
12 While labour mobility is zero in the medium term, capital is assumed to be perfectly mobile, which is a strong assumption too.
} 
Table 7 Results: alternatives with constant preferences and infinite $\eta$ 's

\begin{tabular}{|c|c|c|c|c|c|}
\hline \multirow[t]{2}{*}{ Variable } & \multirow[t]{2}{*}{ Unit } & \multicolumn{2}{|c|}{ Constant preferences } & \multicolumn{2}{|c|}{ Two commodity } \\
\hline & & 2025 & 2040 & 2025 & 2040 \\
\hline Trade balance $\left(b^{\prime}\right)$ & $\%$ GDP & 3.7 & -2.4 & 3.7 & -2.7 \\
\hline Consumer price $(P)$ & Index & 1.05 & 1.13 & 1.05 & 1.07 \\
\hline Consumption $(C)$ & Index & 1.06 & 1.20 & 1.06 & 1.14 \\
\hline Price nontradables/tradables $(x)$ & Index & 1.07 & 1.13 & 1.08 & 1.11 \\
\hline Terms of trade $(\tau)$ & Index & 0.98 & 0.91 & 1.00 & 1.00 \\
\hline Output nontradables/tradables $\left(\sigma_{N}\right)$ & Index & 1.03 & 1.17 & 1.04 & 1.23 \\
\hline Wage nontradables/tradables & Index & 1.08 & 1.12 & 1.13 & 1.17 \\
\hline Employment nontradables/tradables & Index & 1.00 & 1.12 & 1.00 & 1.17 \\
\hline
\end{tabular}

tend to be dampened, as a result of which the deficit in the trade balance is increased. Let us look into the impact of each parameter in more detail

A lower home bias in domestic consumer preferences $(\alpha=1 / 4)$ makes the consumption price less sensitive to changes in domestic aggregate demand because a larger share of consumption is spent on foreign tradables. In comparison with the baseline consumer prices rise by $7.5 \%$ point less, or $7.5 \%$ instead of $15 \%$. Also the terms of trade effect is smaller which is natural as domestic demand is less important domestic tradables producers. Also, less resources are relocated to the nontradables sector as prices of nontradables increase less. This is because with smaller home bias a smaller change in total consumer spending is necessary to achieve a given reversal in the trade balance.

Higher substitution elasticities with regard to home and foreign tradables of domestic and foreign consumers $\left(\eta, \eta^{*}\right)$ lead to smaller price effects as expected. Foreign preferences seem to matter more than preferences of domestic consumers. As it is easier to substitute between home and foreign tradables, there will be stronger reallocation effects between domestic tradables and nontradables sectors as nontradables become relatively scarcer.

Better substitutability between tradables and nontradables in particular reduces the impact on the relative tradables-nontradables price $(x)$. Accordingly, scarcity in the nontradables sector will increase less resulting in smaller wage and price increases and lesser reallocation of resources. The increase in output of nontradables relative to tradables $\left(\sigma_{N}\right)$ diminishes by $8.7 \%$ points from $23 \%$ to about $14 \%$. Finally, larger mobility of labour resulting from a higher $\psi$ leads to a larger reallocation in production—at a smaller wage differential—which dampens the prices effects for consumers. The terms or trade effect increase though, as domestic tradables become more scarce on international markets.

\section{Conclusion}

There are concerns that there will be too little resources in the future to take care of the old when ageing reaches its peak in 2040. Does this analysis take away these 


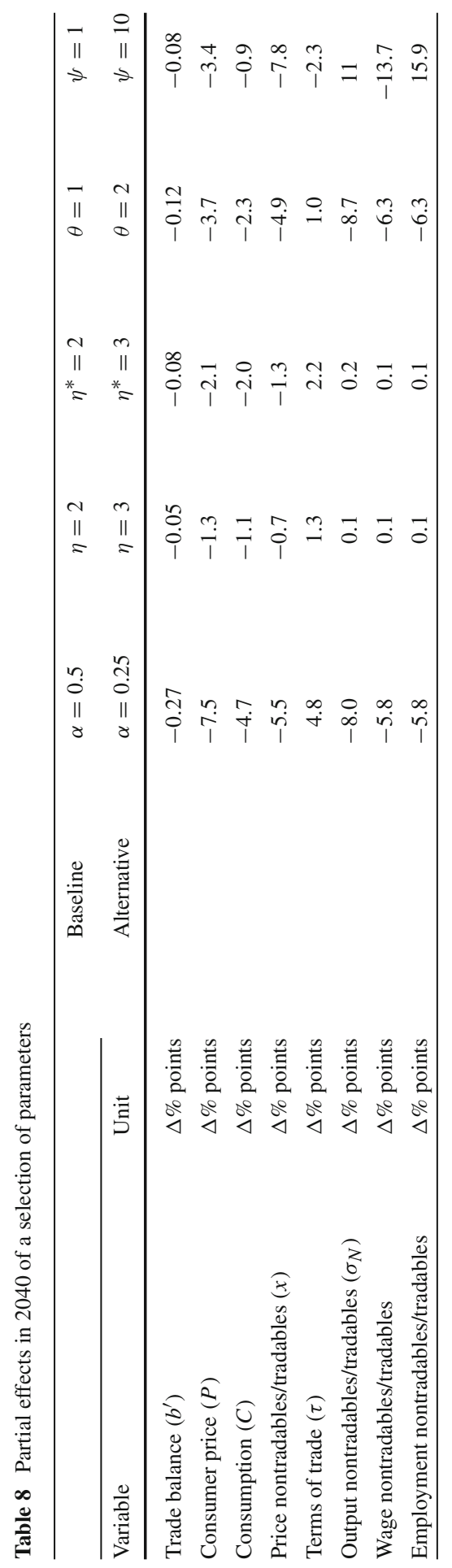


concerns? Yes and no. That ageing of the Dutch population will lead to increasing demand for nontradables (services) in the long run is for sure. Whether this will lead to scarcity and rising wages and prices in the nontradables sector is less certain. This depends on the flexibility of the economy to reallocate resources from the tradables to the nontradables sector on the one hand, and the flexibility of consumers to switch to other, tradable goods and services on the other hand.

Adopting - in our view-conservative estimates on the flexibility of workers and consumers, we find that consumption prices may rise by $15-21 \%$ in total depending on whether you take the baseline projection on ageing or the alternative projection with high growth of care. This amounts to a yearly rise in the real exchange rate by $0.5-0.6 \%$. Prices of nontradables increase by even more, $0.7-0.9 \%$, thereby putting further pressure on the public finances. Interestingly, the change in composition of consumer expenditures plays only a minor role here; it is the unwinding of the trade balance surplus that dominates these results.

Our findings are however sensitive to how flexible we regard the economy over a time horizon of a full generation. Unfortunately, the empirics of such long time horizon is very thin. Looking at wage differentials we do not see big swings in reaction to changes in the large shifts in sectoral allocation that occurred in the past, for example the demise of employment in agriculture and the rise of services industries. Therefore, we interpret the elasticities adopted by Obstfeld and Rogoff in the analysis of the US balance of trade reversal as being at the conservative end of the spectrum. At the same time, neglecting real exchange rate effects at all may be nave as well. Therefore it is important to explore the potential prices effects as we have done in this study.

There are some interesting lessons to be drawn. First of all, while future scarcity of nontradables may drive up the cost of private and public consumption, it will also lead to gains in income through improvement in the terms of trade. On balance, larger scarcity might lead to higher consumption and higher welfare in the long run. Whether this helps the ageing problem depends on which generations benefit from the gains in income. It seems plausible that this will be the younger, working generations, this suggests that these income effects help to diminish the ageing problem, indeed.

One should however be careful in drawing conclusions on welfare, as our analysis is partial and does not represent a full dynamic general equilibrium approach. For example, an interesting issue to be explored in future research is how the real appreciation affects optimal saving behaviour and policies with regard to the ageing problem. Rising domestic prices will lower the real interest rate which might make strategies to increase national savings as a remedy for the ageing problem less attractive. This not only pertains to fiscal policies of the government, but also to the ambition level of pensions. If real interests rates decline, should not we enjoy current consumption more than future consumption?

Open Access This article is distributed under the terms of the Creative Commons Attribution Noncommercial License which permits any noncommercial use, distribution, and reproduction in any medium, provided the original author(s) and source are credited. 


\section{References}

Baldwin, R., \& Robert-Nicoud, F. (2010). Trade-in-goods and trade-in-tasks: An integrating framework. Geneva: Graduate Institute University of Geneva.

Bettendorf, L., van der Horst, A., Draper, N., van Ewijk, C., \& de Mooij, R. (2011). Ageing and the conflict of interest between generations. De Economist, 159, 257-278.

Börsch-Supan, A. (2001). Labor market effects of population ageing. NBER Working Paper 8640. Cambridge, MA: NBER.

Cardi, O., \& Restout, R. (2011). Labor market frictions and the Balassa-Samuelson model. Mimeo, Paris.

CBS. (2009). Kerncijfers van de bevolkingsprognose, 2008-2050. Retrieved from the web (2010, July): http://www.statline.cbs.nl/.

CBS. (2010). Bestedingen; uitgebreide indeling naar huishoudkenmerken (Huurwaarde 2007). Retrieved from the web (2010, July): http://www.statline.cbs.nl/.

CBS. (2011). Nationale Rekeningen; historie. Retrieved from the web (2011-8-29): http://statline.cbs. $\mathrm{nl} /$.

DNB. (2011). Homepage Statistieken, Tabel 12.14 Extern vermogen van Nederlands inclusief BFI's. Retrieved from the web (2011-8-29): http://www.statistics.dnb.nl/.

Eurostat. (2011). Mean consumption expenditure by age of the reference person in PPS (hbs_exp_t135). Retrieved from the web (2011-3-16): http://appsso.eurostat.ec.europa.eu/nui/show. do?wai=true \&dataset=hbs_exp_t135.

Evers, M., de Mooij, R., \& van Vuuren, D. (2008). The wage elasticity of labour supply: A synthesis of emperical estimates. De Economist, 156, 25-43.

Hobijn, B., \& Lagakos, D. (2003). Social security and the consumer price index for the elderly. Federal Reserve Bank of New York. Current Issues in Economics and Finance, 9(5), 1-7.

Horvath, M. (2000). Sectoral shocks and aggregate fluctuations. Journal of Monetary Economics, 45, 69-106.

Iscan, T. B. (2009). How much can Engel's law and Baumol's disease explain the rise of service employment in the United States? Working Paper 2009-03, Department of Economics, Dalhousie University, Halifax.

Lee, D., \& Wolpin, K. J. (2006). Intersectoral labor mobility and the growth of the service sector. Econometrica, 74, 1-46.

Lührmann, M. (2005). Population ageing and the demand for goods and services. Mannheim: MEA, Universität Mannheim.

Lührmann, M. (2008). Effects of population ageing on aggregated UK consumer demand. Paper presented at IFS and CEMMAP, February, 1st, London.

Mendoza, E. (1991). Real business cycles in a small open economy. American Economic Review, 81, 797-818.

Obstfeld M., \& Rogoff, K. (2005). The unsustainable US current account position revisited. National Bureau of Economic Research Working Paper 10869 (Revised edition November 30, 2005).

Oosterbeek, H., \& Webbink, H. D. (1995). Enrolment in higher education in the Netherlands. De Economist, 143, 367-380.

Ostry, J., \& Reinhart, C. (1992). Private saving and terms of trade shocks: Evidence from developing countries. IMF Staff Papers, 39, 495-517.

Stockman, A., \& Tesar, L. (1995). Tastes and technology in a two-country model of the business cycle. American Economic Review, 85, 168-185.

van der Horst, A., Bettendorf, L., Draper, N., van Ewijk, C., de Mooij, R., \& Ter Rele, H. (2010). Vergrijzing verdeeld. Toekomst van de Nederlandse Overheidsfinanciën. CPB Bijzondere Publicatie 86. Den Haag: CPB. 